\title{
Super-microporous organosilicas synthesized from well-defined nanobuilding units $\dagger$
}

\author{
Lei Zhang, ${ }^{a}$ Qihua Yang, ${ }^{* a}$ Hengquan Yang, ${ }^{a}$ Jian Liu, ${ }^{a}$ Hongchuan Xin, ${ }^{a}$ Brahim Mezari, ${ }^{b}$ \\ Pieter C. M. M. Magusin, ${ }^{b}$ Hendrikus C. L. Abbenhuis, ${ }^{b}$ Rutger A. van Santen ${ }^{b}$ and Can Li*a
}

Received 1st October 2007, Accepted 16th November 2007

First published as an Advance Article on the web 29th November 2007

DOI: $10.1039 / b 715031 \mathrm{~h}$

Super-microporous organosilica with bridging ethylene and pendant vinyl groups has been synthesized by assembling predefined nanobuilding block polyhedral oligomeric silsesquioxanes (POSS) with nonionic surfactant Brij-76 as the template. The material shows wormhole-like super-micropores with uniform size of $1.9 \mathrm{~nm}$, high BET surface area of $872 \mathrm{~m}^{2} \mathrm{~g}^{-1}$ and pore volume of $0.52 \mathrm{~cm}^{3} \mathrm{~g}^{-1}$. IR and NMR results show that the bridging ethylene, the pendant vinyl groups and the double-4-membered ring structure were successfully transferred from the building blocks to the super-microporous organosilica material. The material shows high hydrothermal stability and can further react with $\mathrm{Br}_{2}$. The advantage of the present approach lies in that the relative contents and proximity of the different organic functionalities in the final material can be well controlled through the starting nanobuilding blocks.

\section{Introduction}

The discovery of ordered mesoporous silicas (OMSs) has aroused widespread research interest of academic and industrial communities of various disciplines, due to their promising applications in the fields of adsorption, separation and as nanoreactors for catalysis and confined synthesis, etc. ${ }^{1}$ To enrich the composition of OMSs towards specific applications, many synthesis approaches have been proposed. ${ }^{2-4}$ Among others, organo-modification is one of the most versatile and efficient methods to endow mesoporous silicas with miscellaneous functionalities, and has been frequently used for various applications. ${ }^{4}$ The attached organic groups serve as interfacial bridges, enhance the compatibility of the host matrix with the guest species and bring them into interactive intimacy.

Periodic mesoporous organosilicas (PMOs) synthesized from bridged organosilane $(\mathrm{RO})_{3} \mathrm{Si}-\mathrm{R}^{\prime}-\mathrm{Si}(\mathrm{OR})_{3}$ represent one of the most important innovations of organo-modified OMSs by fusing organic and inorganic parts simultaneously and periodically into the pore walls. ${ }^{5}$ To date, numerous PMOs with diverse bridging organic groups, various mesostructures and tunable pore sizes have been reported, and showed promising applications in catalysis, adsorption, separation, low- $k$ films, etc. ${ }^{6}$ In most cases, the pore sizes of these porous organosilicas are larger than $2 \mathrm{~nm}$ and fall in the mesopore range. It has been well established that materials with pore size of 1-2 nm (super-micropore regime) can bridge

${ }^{a}$ State Key Laboratory of Catalysis, Dalian Institute of Chemical Physics, Chinese Academy of Sciences, 457 Zhongshan Road, 116023, Dalian,China.E-mail: yangqh@dicp.ac.cn; canli@dicp.ac.cn;

Fax: (+86) 411-84694447

${ }^{b}$ Schuit Institute of Catalysis, Eindhoven University of Technology, PO Box 513, 5600 MB, Eindhoven, The Netherlands.

Fax: (+31) 40-245-5054

$\uparrow$ Electronic supplementary information (ESI) available: XRD pattern of the sample synthesized by sol-gel transformation of $1 .{ }^{1} \mathrm{H}$ NMR and

${ }^{13} \mathrm{C}$ CP NMR of compound 1. See DOI: $10.1039 / \mathrm{b} 715031 \mathrm{~h}$ the gap between conventional microporous $(<2 \mathrm{~nm})$ and mesoporous $(2-50 \mathrm{~nm})$ materials. Since many organic compounds have molecular sizes of 1-2 nm which surpass the limit of microporous zeolites, super-microporous materials have important impacts on size-specific (shape- and size-selective) applications related to these bulky molecules, such as catalysis, adsorption and sequestration. ${ }^{7}$ Moreover, super-microporous materials are also potential candidates for the confined synthesis of nanoparticles and nanowires with size/diameter of 1-2 nm. However, compared with the well-developed microporous and mesoporous materials, the synthesis of super-microporous materials has remained a challenge. Super-microporous materials have been synthesized with short chain surfactants, ${ }^{7 a-f}$ or some specifically designed templates, ${ }^{7 g-k}$ as well as some special oligomeric precursors. ${ }^{7 l, m}$ Albeit important, the reports on the synthesis of supermicroporous organosilicas are quite few. Mercier et al. reported the synthesis of ethylene-bridged organosilicas with pore sizes of 1-2 nm using short chain alkylamine or alkyl(phenyl)polyethylene oxide surfactants under neutral to weakly acidic conditions. ${ }^{7 f}$ To the best of our knowledge, this is the only report of super-microporous organosilicas so far.

Despite the ever-expanding composition spectrum of PMOs, most bridging groups are chemically inert, which also limits their applications. ${ }^{6}$ To overcome this problem, PMOs have been modified by co-condensation of $(\mathrm{RO})_{3} \mathrm{Si}-\mathrm{R}^{\prime}-\mathrm{Si}(\mathrm{OR})_{3}$ with another organosilane $\mathrm{R}^{\prime \prime}-\mathrm{Si}(\mathrm{OR})_{3}$, thereby generating the so-called bifunctional PMOs (BPMOs). ${ }^{8}$ Although the cocondensation method has proven effective and been frequently utilized to yield various hybrid catalysts and sorbents, ${ }^{8,9}$ it is still difficult to achieve stoichiometric incorporation and defined distribution of the two organic groups in the framework due to the different hydrolysis-condensation kinetics of the organosilanes. A more efficient and controllable method is desired for the synthesis of multifunctional mesoporous materials, especially BPMOs. 
The recently developed nanobuilding-block-assembly approach for the synthesis of mesoporous organosilicas has enabled one to define the fine structure of the materials in the starting nanobuilding blocks. ${ }^{10}$ Herein, we report the synthesis of a novel bifunctional super-microporous organosilicas via this nanobuilding-block-assembly approach. A polyhedral oligomeric silsesquioxane (POSS) compound, with built-in bifunctionality of bridging ethylene and pendant vinyl groups, is designed and used as the starting nanobuilding block. By assembling the predefined POSS units around the templates (Brij-76 micelles) and subsequent removal of the templates via extraction, bifunctional supermicroporous organosilica was synthesized. The material shows high hydrothermal stability due to the presence of $\mathrm{R}-\mathrm{Si}$ bonds, the ethylene and vinyl groups, and the precondensed silsesquioxane cage. The vinyl groups in the supermicroporous organosilica can be transformed into new functionalities by bromination.

\section{Experimental}

Synthesis

Synthesis of super-microporous organosilica. POSS compound 1 was synthesized according to the reported procedure (Scheme 1). ${ }^{10}$ For the synthesis of super-microporous organosilica, $0.40 \mathrm{~g}$ of Brij-76 (Aldrich) was dissolved in $12.0 \mathrm{~g}$ of aqueous $\mathrm{HCl}$ solution $(0.5 \mathrm{M})$. The mixture was stirred for $2 \mathrm{~h}$ at $326 \mathrm{~K} .0 .58 \mathrm{~g}$ of 1 was dissolved in $0.5 \mathrm{~mL}$ of butanol and slowly added into the Brij-76 solution under vigorous stirring. The resulting mixture was further stirred for $24 \mathrm{~h}$ at the same temperature. The white precipitate was finally recovered by filtration.
To release the Brij-76 template species, $1.0 \mathrm{~g}$ of the assynthesized sample was stirred in $200 \mathrm{~mL}$ of ethanol at $343 \mathrm{~K}$ for $24 \mathrm{~h}$. This process was repeated once followed by Soxhlet extraction with ethanol for an additional $24 \mathrm{~h}$. The sample thus obtained was dried under vacuum and denoted as SPMicPOSS, abbreviated from super-microporous POSS.

Reaction of SPMic-POSS with $\mathbf{B r}_{2}$. To test the accessibility of the vinyl groups in the hybrid materials, bromination reaction was performed. An open vial containing $0.2 \mathrm{~g}$ of SPMic-POSS sample was placed in a vessel containing $1.0 \mathrm{~g}$ of liquid bromine. The sample was brominated under the bromine vapor for $2 \mathrm{~d}$ at ambient temperature. The resulting yellow powder was thoroughly washed with dichloromethane until the powder turned white. The recovered sample was denoted as SPMic-POSS-Br.

\section{Characterization}

The nitrogen sorption experiments were performed at $77 \mathrm{~K}$ on an ASAP 2020 system. Samples were degassed at $393 \mathrm{~K}$ for $5 \mathrm{~h}$ prior to the measurements. X-Ray powder diffraction (XRD) patterns were recorded on a Rigaku D/Max 3400 powder diffraction system using $\mathrm{CuK} \alpha$ radiation of wavelength $0.1542 \mathrm{~nm}$. Transmission electron microscopy (TEM) was performed with a FEI Tecnai $\mathrm{G}^{2}$ Spirit at an acceleration voltage of $120 \mathrm{kV}$. FT-IR spectra were recorded using a Nicolet Nexus 470 IR spectrometer with $\mathrm{KBr}$ pellets. ${ }^{29} \mathrm{Si}$ MAS NMR and ${ }^{13} \mathrm{C}$ CP MAS NMR spectra were recorded on a Bruker DMX500 spectrometer. For ${ }^{13} \mathrm{C}$ CP MAS NMR experiments, $6 \mathrm{kHz}$ spin rate, $3 \mathrm{~s}$ pulse delay, and 2000 scans; for ${ }^{29} \mathrm{Si}$ MAS NMR experiments, $6 \mathrm{kHz}$ spin rate, $3 \mathrm{~s}$ pulse delay, and 1000 scans.
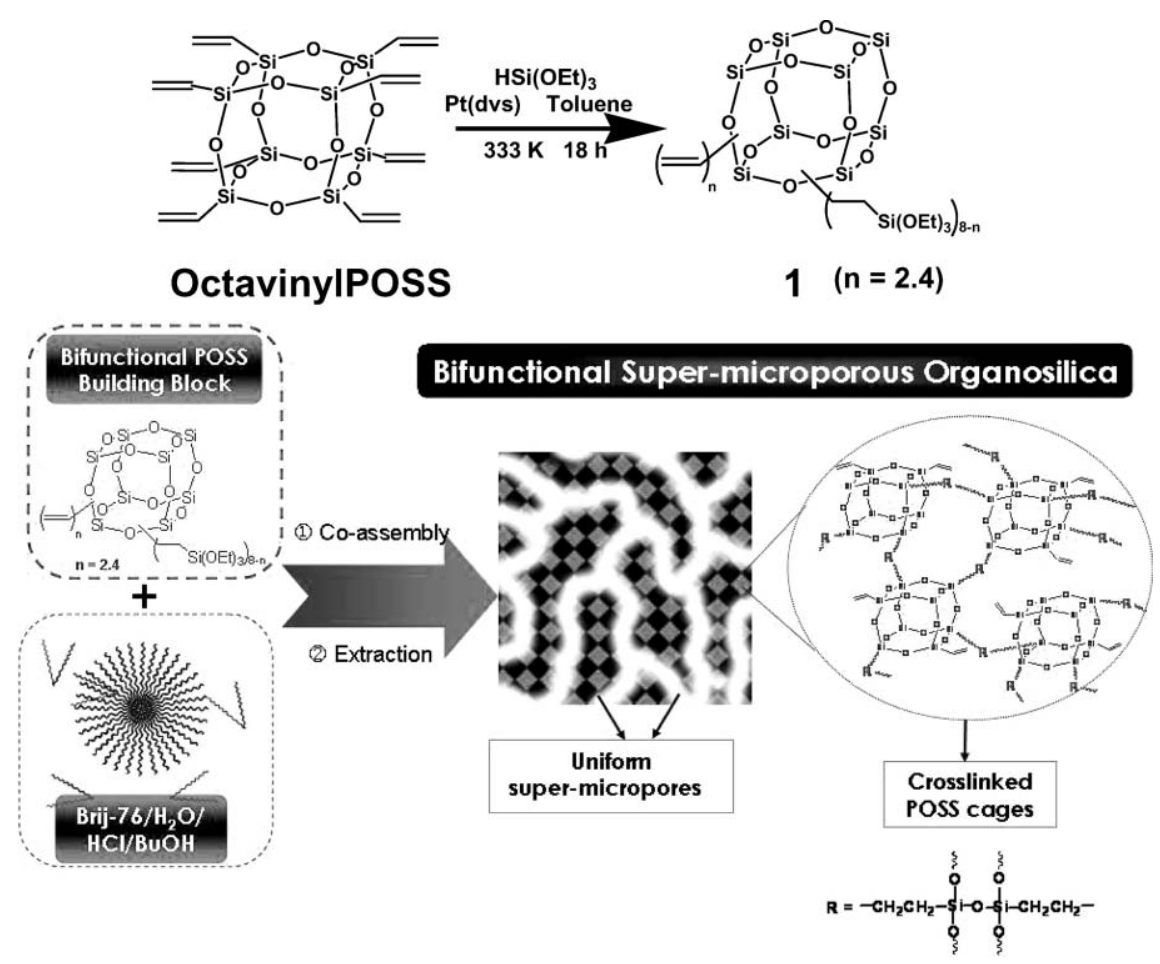

Scheme 1 Synthesis procedure and the proposed structure of the super-microporous organosilica SPMic-POSS. 


\section{Results and discussion}

\section{Synthesis and textural properties of the super-microporous organosilica SPMic-POSS}

We first synthesized a nanobuilding block carrying bridging ethylene and pendant vinyl groups. ${ }^{10}$ The starting core we used was octavinyl-substituted POSS octamer $\left(\mathrm{CH}_{2}=\mathrm{CH}\right)_{8} \mathrm{Si}_{8} \mathrm{O}_{12}\left(\right.$ OctavinylPOSS $\left.{ }^{\mathbb{R}}\right)$, which can be obtained via the controlled hydrolysis-condensation of vinylsilane. POSS compound $\mathbf{1}$ was synthesized through hydrosilylation of OctavinylPOSS ${ }^{\circledR}$ with substoichiometric $\mathrm{HSi}(\mathrm{OEt})_{3}$ $\left(\mathrm{HSi}(\mathrm{OEt})_{3}:\right.$ OctavinylPOSS $=6: 1$, instead of $\left.8: 1\right)$. NMR and MALDI-TOF spectra revealed that compound $\mathbf{1}$ was a mixture of POSS with different vinyl substitution degrees and the average number of remnant vinyl groups per cage was estimated to be 2.4. ${ }^{10}$ The hybrid material was built by hydrolysis-condensation of compound $\mathbf{1}$ around Brij-76 micelles. Subsequent removal of the Brij-76 via extraction left pores throughout the material (Scheme 1). The material thus obtained was denoted as SPMic-POSS. The overall synthesis procedure of SPMic-POSS can be regarded as a step-by-step assembly approach from (trialkoxy)silyl compounds. This stepwise synthesis process ensures that the relative content and distribution of the two functional groups, bridging ethylene and pendant vinyl groups in this case, can be predefined in the nanobuilding block.

The porous structure of SPMic-POSS was first investigated with nitrogen sorption measurement. The material shows a BET surface area of $872 \mathrm{~m}^{2} \mathrm{~g}^{-1}$ and a total pore volume of $0.52 \mathrm{~cm}^{3} \mathrm{~g}^{-1}$. The isotherm appears to be a transition from type IV for mesoporous materials to type I for microporous materials (Fig. 1a). No apparent hysteresis loop can be observed. This indicates that SPMic-POSS has supermicroporous structure. ${ }^{7,11}$ The pore size distribution curve derived from the adsorption branch confirms this and shows a peak at $1.9 \mathrm{~nm}$ (Fig. 1b).

The synthesis of super-microporous materials has been difficult unless some short chain surfactant or some specifically designed templates are employed. ${ }^{7}$ It is surprising that supermicroporosity is generated with Brij-76 as the template, since

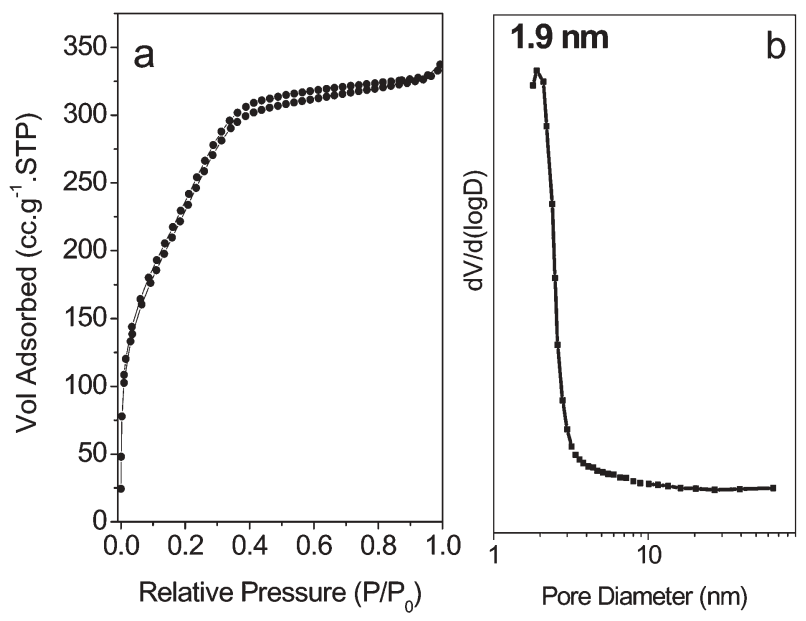

Fig. 1 (a) Nitrogen sorption isotherm of SPMic-POSS and (b) the pore size distribution curve derived from the adsorption branch. the pore sizes of porous silicas ${ }^{12}$ and organosilicas ${ }^{13}$ templated with Brij-76 under acidic conditions often fall in the range of 3.0 to $5.5 \mathrm{~nm}^{12,13} \mathrm{We}$ suppose that the origin of supermicroporosity in the current system is related to the special structure of POSS compound 1. Brij-76 $\left[\mathrm{C}_{18} \mathrm{H}_{37}\left(\mathrm{OC}_{2} \mathrm{H}_{4}\right)_{10} \mathrm{H}\right]$ is a non-ionic surfactant consisting of a hydrophobic octadecyl chain and hydrophilic poly(ethylene oxide). It has been generally accepted that for the nanoporous materials synthesized with Brij-76 as the template, the formation of the mesophase is driven by the hydrogen-bonding interactions between the oligomeric inorganic precursors and hydrophilic poly(ethylene oxide). ${ }^{12-14}$ Compound $\mathbf{1}$ is a silsesquioxane compound with hydrophobic bridging ethylene and pendant vinyl groups. Compared with silica and organosilica oligomers derived from molecular precursors, the bulky and rigid cage structure of the POSS reduces the silanol group density and hence the surface charge density of the POSS oligomer, which will render the POSS oligomer more hydrophobic and weaken the interactions of the POSS oligomer with the hydrophilic poly(ethylene oxide) chains. As a result, deep penetration of the POSS oligomer towards the micelle core can be expected, which will consequently decrease the effective pore size. On the other hand, due to the non-site-specific hydrosilylation reaction of OctavinylPOSS, compound $\mathbf{1}$ is actually a mixture of POSS cages with different vinyl substitution degrees. Considering the steric hindrance, the cages with fewer (triethoxy)silyl arms will behave more like an organosilane with a pendant organic group, and are more prone to penetrate into the micelles. Moreover, the bulky and rigid cages may exert more strain upon polymerization than molecular precursors, which will also cause smaller pore sizes.

The porous structure of SPMic-POSS was further investigated with XRD and TEM techniques. The small-angle XRD pattern shows a strong diffraction peak at two theta of $1.56^{\circ}$ (Fig. 2a), which corresponds to a $d$ spacing of $5.7 \mathrm{~nm}$. The appearance of a single diffraction peak indicates that the material has a wormhole-like porous structure, similar to that of the MSU-type materials. ${ }^{14}$ The TEM image corroborates this by showing interlaced uniform super-micropores with mean size $<2 \mathrm{~nm}$ throughout the bulk phase (Fig. 3).
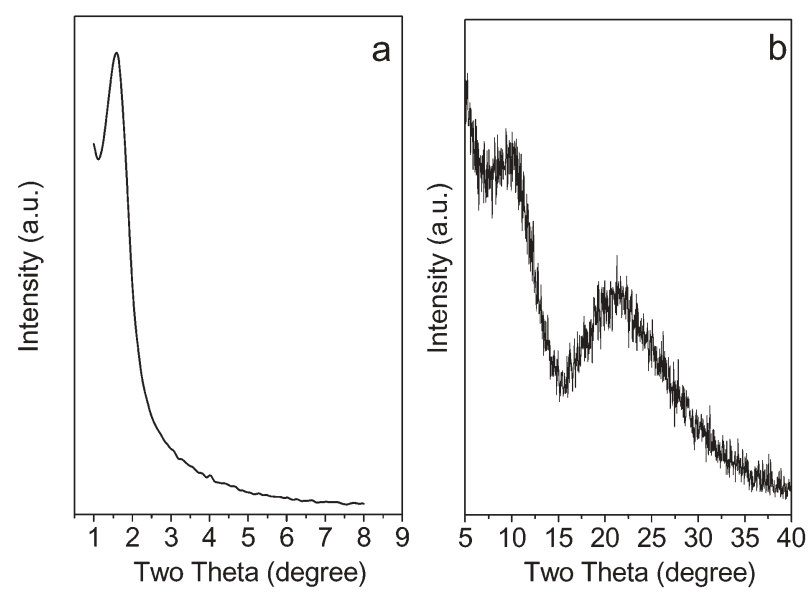

Fig. 2 (a) Small angle XRD pattern and (b) wide angle XRD pattern of SPMic-POSS. 


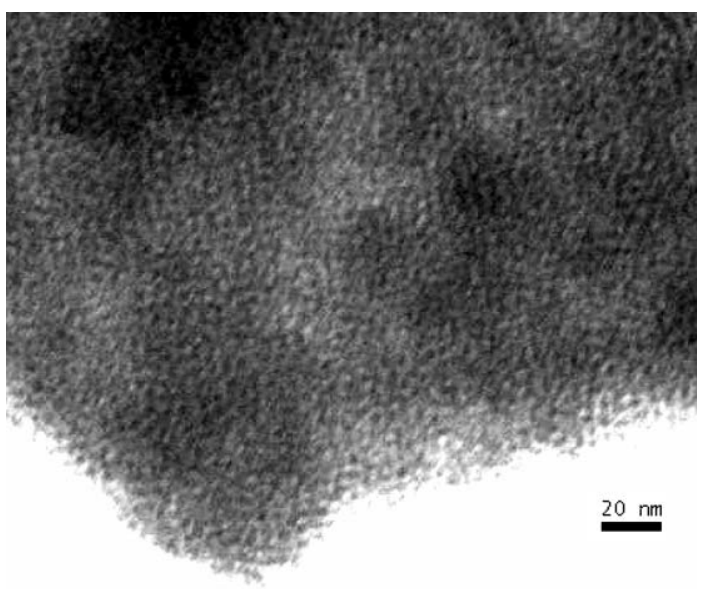

Fig. 3 TEM image of SPMic-POSS.

It is noted that under similar synthesis conditions with Brij-76 as the template, ordered 2D or 3D mesophases can be obtained from molecular precursors, such as tetraalkoxysilane and bridged organosilanes. ${ }^{12,13}$ Several possible complications related to the structure of compound $\mathbf{1}$ may limit the formation of an ordered mesophase. Firstly, as discussed above, the hydrophobicity and low silanol density of compound 1 weaken the interaction between the POSS oligomer and the hydrophilic poly(ethylene oxide) corona of Brij-76, which will result in a loose supramolecular structure and partial penetration of the POSS through the palisade towards the micelles interior. This is adverse to the co-assembly process for the formation of an ordered mesophase by interfering with the hydrophilic/ hydrophobic phase segregation. Secondly, the size of compound 1 is estimated to be around $1-2 \mathrm{~nm},{ }^{15}$ which represents one of the biggest organosilane building blocks for the synthesis of porous hybrid materials thus far. ${ }^{16}$ Considering the steric limitations, it is difficult for such a big and rigid block to highly crosslink into an infinite and stable network through the short ethylene arms, while still possessing a flexible configuration compromising the high curvature at the micelle interface needed for the formation of an ordered phase. Meanwhile, the strain exerted by the polymerization of the POSS units will also affect the micelle structure.

It is interesting to note that, in addition to the small-angle peak related to the porous structure, the wide angle XRD pattern exhibits an additional broad peak around two theta of $10^{\circ}$ beside the amorphous halo peak at $22^{\circ}$ (Fig. 2b). For mesoporous materials, such wide-angle diffraction peaks have only been observed in limited cases of those with molecular periodicity in the pore walls. ${ }^{17,18}$ Laine et al. also observed a similar broad peak in their POSS polymer prepared by hydrosilylation and attributed it to the repeat of POSS cages in the polymer framework. ${ }^{19}$ Thus, this broad peak may reflect, to some extent, the periodic arrangement of the POSS units in the framework of SPMic-POSS. Meanwhile, this result also implies that the cage structure is preserved. As a further proof, a control sample was prepared under mild conditions without template by exposing compound $\mathbf{1}$ to ambient moisture at room temperature and allowing it to undergo slow gelation. The XRD pattern of this sample also exhibits a similar broad peak around $10^{\circ}$, thus confirming that the POSS cages of compound $\mathbf{1}$ are intact during the assembly process (ESI† Fig. S1).

\section{Framework composition of SPMic-POSS}

To determine the transferring efficiency of the functionality from the starting building units into the final hybrid material, FT-IR and NMR measurements were performed on SPMic-POSS.

Shown in Fig. 4 are the comparative IR spectra of OctavinylPOSS, 1 and SPMic-POSS. The existence of the vinyl group in compound $\mathbf{1}$ and the hybrid material SPMic-POSS was confirmed by the adsorption bands at 1604 (stretching vibration mode of $\mathrm{C}=\mathrm{C}$ ), 3024 and $3067 \mathrm{~cm}^{-1}$ (stretching vibration of $\mathrm{C}-\mathrm{H}$ in $=\mathrm{CH}-$ and $=\mathrm{CH}_{2}$ in the vinyl groups, respectively). ${ }^{20}$ Bands at 2890 and $2925 \mathrm{~cm}^{-1}$ in compound 1 and SPMic-POSS can be ascribed to the symmetric and asymmetric $\mathrm{C}-\mathrm{H}$ vibration of the bridging ethylene group, respectively. ${ }^{21}$ It is interesting to note that an adsorption band at $564 \mathrm{~cm}^{-1}$ was observed for SPMic-POSS. For silica-based materials, bands in the range of $500-600 \mathrm{~cm}^{-1}$ can only be observed in zeolites or those having zeolite-like framework, and usually arise from the skeletal vibration of subunits with ring structures. ${ }^{18 a-c, 22}$ In the same range, an adsorption band at $585 \mathrm{~cm}^{-1}$ was observed for OctavinylPOSS. Upon hydrosilylation, this peak shifts to $572 \mathrm{~cm}^{-1}$ for compound 1. After the hydrolysis-condensation, this band further shifts to the lower wavenumber of $564 \mathrm{~cm}^{-1}$ for SPMic-POSS. On the basis of the structure of compound $\mathbf{1}$, we attribute this band to the skeletal vibration of double-4membered rings (D4R) of the POSS cage. The gradual shift of this adsorption band reflects the stepwise structure transformations around the D4R. IR results indicate that the D4R was integrated into the final hybrid materials, which is consistent with the XRD results.

Fig. 5 displays the ${ }^{13} \mathrm{C} \mathrm{CP}$ MAS and ${ }^{29} \mathrm{Si}$ MAS NMR results of SPMic-POSS. Four sets of peaks can be observed in the ${ }^{13} \mathrm{C}$ NMR spectrum (Fig. 5a). The peak centered at 5.0 ppm can be ascribed to the carbon species of the bridging ethylene group $\left[\equiv \mathrm{Si}-\mathrm{CH}_{2} \mathrm{CH}_{2}-\mathrm{Si} \equiv\right]$, in accordance with the reported results of ethylene-bridged PMO materials. ${ }^{21}$ The peaks at 16.5 and 58.4 ppm arise from the methyl and methylene carbons in the

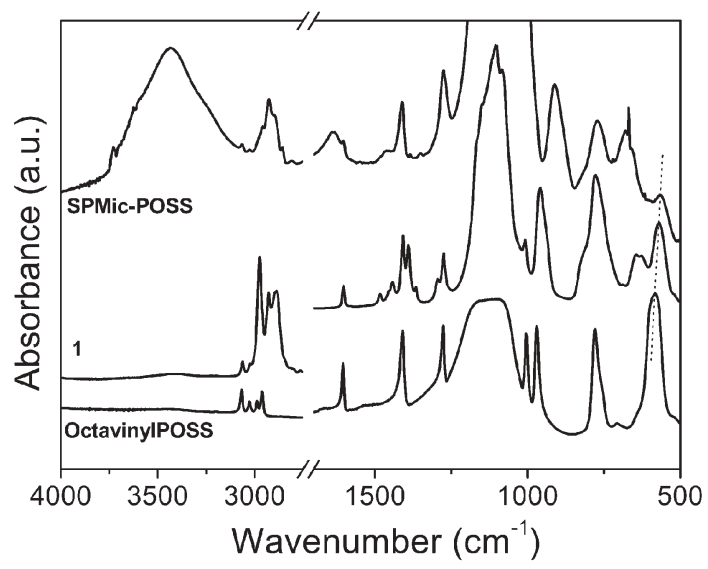

Fig. 4 IR spectra of OctavinylPOSS, compound 1 and SPMic-POSS. 

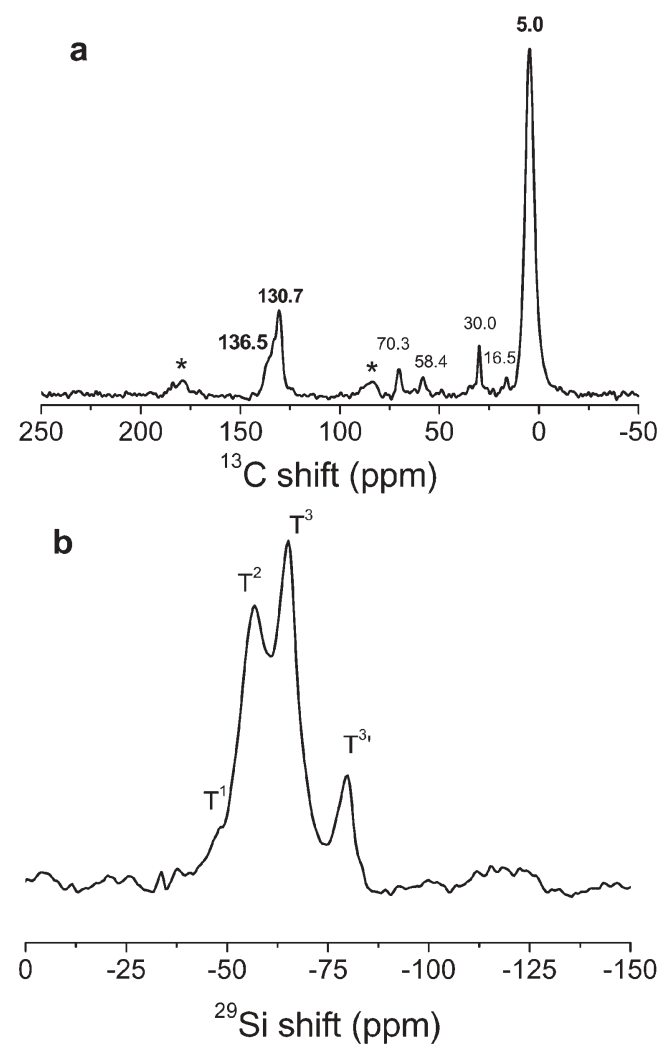

Fig. 5 (a) ${ }^{13} \mathrm{C}$ CP MAS NMR and (b) ${ }^{29} \mathrm{Si}$ MAS NMR spectra of SPMic-POSS

ethoxy groups $\left[\left(\mathrm{CH}_{3} \mathrm{CH}_{2} \mathrm{O}\right)_{m}-\mathrm{Si} \equiv\right](m=1,2),{ }^{23}$ respectively, as also observed in the starting compound 1 (ESI $\dagger$ Fig. S2). Considering the steric hindrance, it is difficult to assemble all the building blocks into one entity by crosslinking each vertex (triethoxy)silyl group completely. Thus, it is reasonable to observe that some ethoxy groups were not hydrolyzed and remained in the final materials. Moreover, extraction of the Brij-76 with ethanol also generates some ethoxy groups through the reaction of ethanol with the silanol groups. ${ }^{23}$ The peaks around 30.0 and $70.3 \mathrm{ppm}$ are attributed to the remnant Brij-76. ${ }^{24}$ It should be noted that, compared with mesoporous silica and PMO materials, it may be more difficult to remove the template completely for SPMic-POSS. One possible reason could be the deep occlusion of some small template pigments in the voids between the cages, which is caused by the penetration of hydrophobic POSS into the micelles. The last two broad peaks around 130.7 and $136.5 \mathrm{ppm}$ can be ascribed to the pendant vinyl carbons. ${ }^{20}$

The ${ }^{29} \mathrm{Si}$ NMR spectrum of SPMic-POSS shows three broad peaks centered at $-56.9,-65.0$ and $-79.6 \mathrm{ppm}$, together with a small shoulder at -48.9 ppm (Fig. 5b). These can be categorized into two kinds of $\mathrm{T}$ silicon sites with different substitution environments. The first set of $\mathrm{T}$ peaks corresponds to silicon atoms bonded to bridging ethylene, $-48.9 \mathrm{ppm}$ for $\mathrm{T}^{1}\left[-\mathrm{CH}_{2} \mathrm{CH}_{2}-\mathrm{Si}(\mathrm{OSi})(\mathrm{OH})_{2}\right],-56.9 \mathrm{ppm}$ for $\mathrm{T}^{2}\left[-\mathrm{CH}_{2} \mathrm{CH}_{2}-\right.$ $\left.\mathrm{Si}(\mathrm{OSi})_{2}(\mathrm{OH})\right]$, and $-65.0 \mathrm{ppm}$ for $\mathrm{T}^{3}\left[-\mathrm{CH}_{2} \mathrm{CH}_{2}-\mathrm{Si}(\mathrm{OSi})_{3}\right] .{ }^{21}$ The last peak at $-79.6 \mathrm{ppm}$ corresponds to fully condensed silicon sites connected to the pendant vinyl groups as $\mathrm{T}^{3^{\prime}}$ $\left[\mathrm{CH}_{2}=\mathrm{CH}-\mathrm{Si}(\mathrm{OSi})_{3}\right]{ }^{25}$ These results confirm the FT-IR results that both functional groups are retained in the final materials. No peak related to $\mathrm{T}^{2^{\prime}}\left[\mathrm{CH}_{2}=\mathrm{CH}-\mathrm{Si}(\mathrm{OSi})_{2}(\mathrm{OH}), \sim-70 \mathrm{ppm}\right]$ was observed. ${ }^{25}$ Moreover, by integrating the peak areas $\left(S_{\mathrm{T}}\right)$, the different $\mathrm{T}$ sites exhibit a peak area ratio of $\Sigma S_{\mathrm{T}}{ }^{n} / \Sigma S_{\mathrm{T}}{ }^{n^{\prime}} \approx$ 6.0, which agrees with the structure of compound 1. These results further reveal that the cage structure of POSS is retained during the synthesis and transferred into the final materials, in accordance with the FT-IR results.

\section{Hydrothermal stability of SPMic-POSS}

For most mesoporous materials, the hydrothermal stability has long been a big issue limiting their practical applications. Several approaches have been proposed to enhance the hydrothermal stability of mesoporous materials. These include improving the framework condensation degree by hightemperature synthesis with fluorocarbon surfactant, ${ }^{26 a}$ by adding cation additives, ${ }^{26 b-d}$ or by using zeolitic precursors. ${ }^{22}$ Alternatively, hydrothermal stability can also be improved by post-modification of a surface with hydrophobic groups, ${ }^{27 a}$ or using bridged organosilanes as the precursors. ${ }^{24,27 b-27 e}$

In the present case, both the organic groups and the precondensed POSS cage are expected to benefit the hydrothermal stability of SPMic-POSS. To address this issue, SPMic-POSS was treated in refluxing water for $125 \mathrm{~h}$. The sample thus obtained is denoted as SPMic-POSS-H. Fig. 6 shows the comparative XRD patterns of SPMic-POSS and SPMicPOSS-H. The appearance of one strong peak in the smallangle range, albeit with lowered intensity compared with that of SPMic-POSS, indicates that the porous structure is retained. The textural changes were evaluated with nitrogen sorption measurements.

Shown in Fig. 7 are the comparative nitrogen sorption isotherms and the corresponding pore size distribution curves. After the hydrothermal treatment, the capillary condensation step in the isotherm of SPMic-POSS-H shifts towards higher relative pressure and becomes steeper compared to that of SPMic-POSS, which indicates the enlargement of pore diameter. The isotherm changes to type IV for typical mesoporous materials. The BJH pore size distribution curve shows that, after the hydrothermal treatment, the pore size evolved

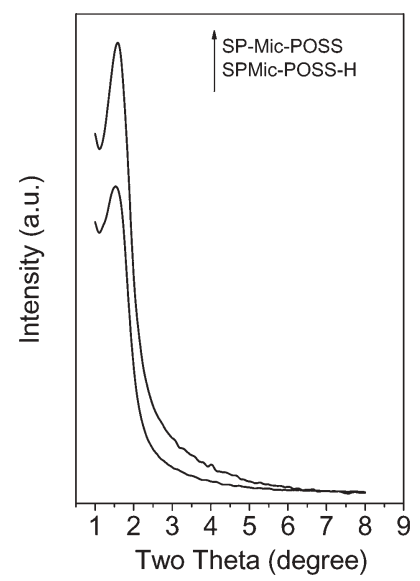

Fig. 6 Small angle XRD pattern of SPMic-POSS and the hydrothermally treated sample SPMic-POSS-H. 

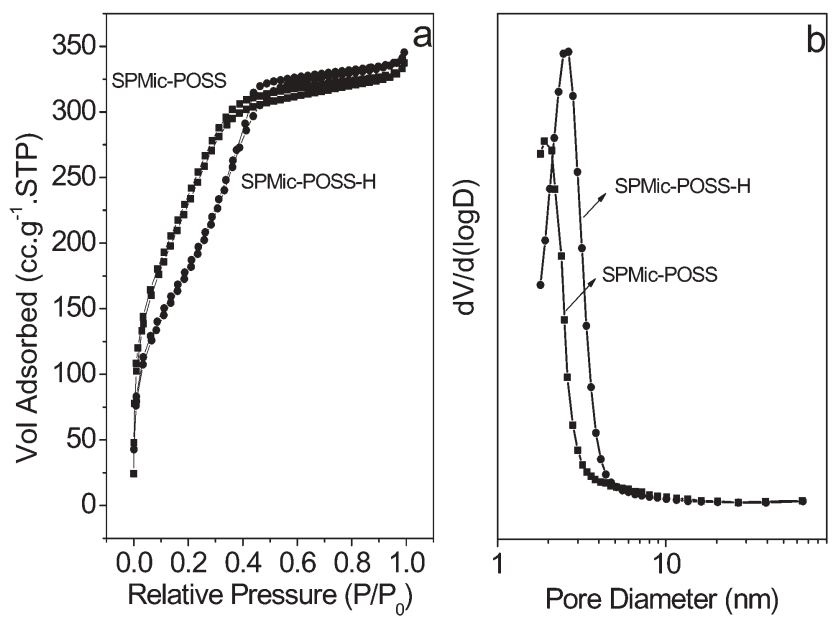

Fig. 7 (a) Nitrogen sorption isotherms and (b) the corresponding pore size distribution curves of SPMic-POSS and SPMic-POSS-H.

from super-microporous $(1.9 \mathrm{~nm})$ into the mesoporous range $(2.6 \mathrm{~nm})$. This may result from further framework condensation. The total pore volume remains virtually unchanged $\left(0.52\right.$ vs. $\left.0.53 \mathrm{~cm}^{3} \mathrm{~g}^{-1}\right)$, whereas the BET surface area decreases from 872 to $675 \mathrm{~m}^{2} \mathrm{~g}^{-1}$ due to the pore expansion. Nevertheless, the above results show that SPMicPOSS has a relatively high hydrothermal stability, which surpasses that of the silica counterparts and is comparable with that of the organosilica counterparts. ${ }^{27}$

\section{Reaction of SPMic-POSS with $\mathrm{Br}_{2}$}

To evaluate the accessibility of the vinyl groups in SPMicPOSS, a simple bromination reaction was performed. ${ }^{20}$ Fig. 8 shows the comparative IR spectra of sample SPMic-POSS and the brominated sample SPMic-POSS-Br. After bromination, peaks at 1604, 3024 and $3067 \mathrm{~cm}^{-1}$, which correspond to the vibration modes of the vinyl groups, virtually disappeared. This indicates that the double bonds have been converted. To confirm this, the ${ }^{13} \mathrm{C}$ CP MAS NMR spectrum was recorded (Fig. 9). For sample SPMic-POSS-Br, peaks corresponding to vinyl carbons in the range of 130 to $137 \mathrm{ppm}$ disappeared,

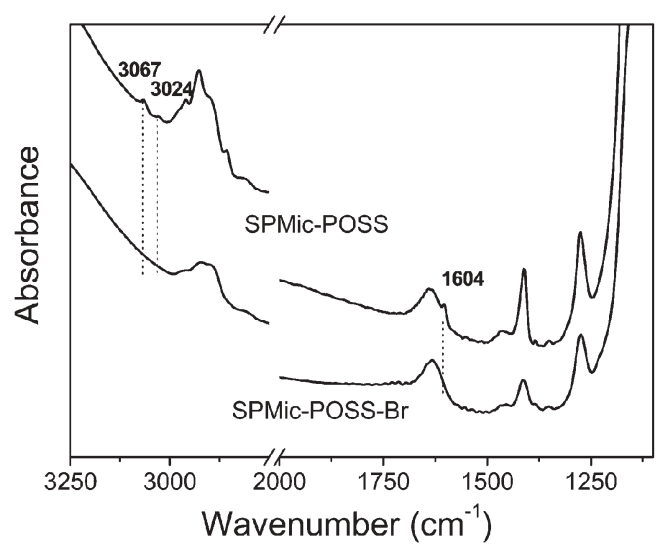

Fig. 8 IR spectra of SPMic-POSS and the brominated sample SPMic-POSS-Br.

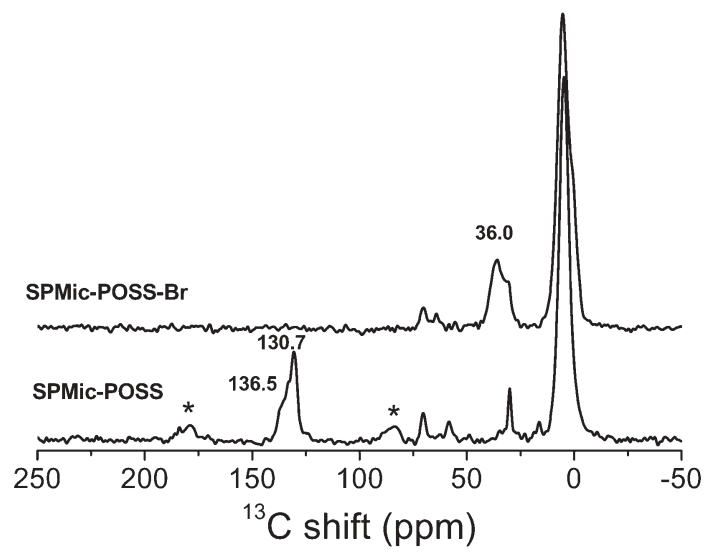

Fig. $9{ }^{13} \mathrm{C}$ CP MAS NMR spectra of SPMic-POSS and the brominated sample SPMic-POSS-Br.

along with the appearance of a new broad peak at $36.0 \mathrm{ppm}$. The latter can be ascribed to the brominated carbons according to the previous report. ${ }^{20}$ Thus, FT-IR and NMR results show that the vinyl groups are highly accessible and can be completely converted by bromination.

An important issue which should be considered is the effect of bromination on the textural properties of the material. To clarify this, small-angle XRD and nitrogen sorption measurements were performed for sample SPMic-POSS-Br. One diffraction peak was observed for SPMic-POSS-Br, indicating that the porous structure survived the bromination (Fig. 10a). The lowered intensity for SPMic-POSS-Br may be partly due to the decreased X-ray scattering contrast between the pore walls and the pore space induced by the surface modification. Shown in Fig. 10b are the nitrogen sorption isotherm and the corresponding $\mathrm{BJH}$ pore size distribution curve. Upon bromination, slight decreases in pore volume $(0.52$ vs. $\left.0.47 \mathrm{~cm}^{3} \mathrm{~g}^{-1}\right)$ and BET surface area $\left(872\right.$ vs. $\left.849 \mathrm{~m}^{2} \mathrm{~g}^{-1}\right)$ were observed. However, since both specific surface area and pore volume are associated with the mass of the sample, the mass increase upon bromination should be taken into account. The isotherm for SPMic-POSS-Br is similar to that of SPMic-POSS

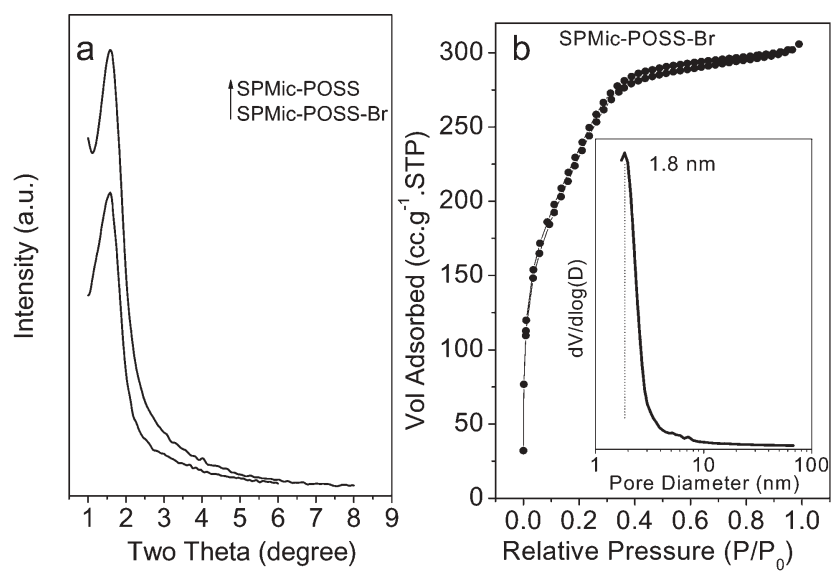

Fig. 10 (a) Small angle XRD patterns of SPMic-POSS and the brominated sample SPMic-POSS-Br; (b) nitrogen sorption isotherm and the corresponding pore size distribution curve of SPMic-POSS-Br. 
despite the slightly lowered adsorption amount, indicating that the porous structure was retained. The BJH pore size distribution curve shows that the pore diameter slightly decreased from 1.9 to $1.8 \mathrm{~nm}$, remaining in the supermicroporous range.

\section{Conclusion}

In summary, bifunctional super-microporous organosilica with bridging ethylene and pendant vinyl groups has been synthesized by assembling predefined POSS nanobuilding blocks around a Brij-76 template. The formation of the unique super-microporous structure is proposed to be related to the unique structure and hydrophobic characteristic of the POSS unit. The material exhibits high hydrothermal stability and the porous structure was preserved after being treated in boiling water for $125 \mathrm{~h}$. The reactive vinyl groups in the material are highly accessible and can easily react with $\mathrm{Br}_{2}$. The present strategy provides an opportunity for the designer synthesis of multi-functional super-microporous materials, wherein the relative contents and proximity of different functional groups can be predefined by tailoring the nanobuilding blocks. Especially for materials with interactive multi-functional groups, the cooperative symphony between different groups can be envisioned and determined prior to the building process of the materials. By combining the versatile co-assembly approaches and the rich POSS chemistry, numerous functionalized nanoporous materials are conceivable.

\section{Acknowledgements}

This work was supported by the Programme for Strategic Scientific Alliances between China and the Netherlands (PSA), 04-PSA-M-01, NSFC 20321303 and National Basic Research Program of China (2003CB615803).

\section{References}

1 (a) M. E. Davis, Nature, 2002, 417, 813; (b) G. J. A. A. Soler-Illia, C. Sanchez, B. Lebeau and J. Patarin, Chem. Rev., 2002, 102, 4093; (c) A. Corma, Chem. Rev., 1997, 97, 2373; (d) S. Polarz and B. Smarsly, J. Nanosci. Nanotechnol., 2002, 2, 581.

2 (a) C. Yu, B. Tian and D. Y. Zhao, Curr. Opin. Solid State Mater. Sci., 2003, 7, 191; (b) F. Schüth, Chem. Mater., 2001, 13, 3184.

3 (a) C. G. Wu and T. Bein, Science, 1994, 264, 1757; (b) T. Q. Nguyen, J. J. Wu, V. Doan, B. J. Schwartz and S. H. Tolbert, Science, 2000, 288, 652; (c) M. Choi, F. Kleitz, D. Liu, H. Y. Lee, W. S. Ahn and R. Ryoo, J. Am. Chem. Soc., 2005, 127, 1924; (d) K. Kageyama, J. Tamazawa and T. Aida, Science, 1999, 285, 2113.

4 (a) A. Stein, B. J. Melde and R. C. Schroden, Adv. Mater., 2000, 12, 1403; (b) A. Sayari and S. Hamoudi, Chem. Mater., 2001, 13, 3151; (c) F. Hoffmann, M. Cornelius, J. Morell and M. Fröba, Angew. Chem., Int. Ed., 2006, 45, 3216.

5 (a) S. Inagaki, S. Guan, Y. Fukushima, T. Ohsuna and O. Terasaki, J. Am. Chem. Soc., 1999, 121, 9611; (b) B. J. Melde, B. T. Holland, C. F. Blanford and A. Stein, Chem. Mater., 1999, 11, 3302; (c) T. Asefa, M. J. MacLachlan, N. Coombs and G. A. Ozin, Nature, 1999, 402, 867.

6 (a) F. Hoffmann, M. Cornelius, J. Morell and M. Fröba, J. Nanosci. Nanotechnol., 2006, 6, 265; (b) B. Haton, K. Landskron, W. Whitnall, D. Perovic and G. A. Ozin, Acc. Chem. Res., 2005, 38, 305.

7 (a) Y.-S. Lin, H.-P. Lin and C.-Y. Mou, Microporous Mesoporous Mater., 2004, 76, 203; (b) K. Yano and Y. Fukushima, J. Mater. Chem., 2003, 13, 2577; (c) E. Bastardo-Gonzalez, R. Mokaya and
W. Jones, Chem. Commun., 2001, 1016; (d) Y. Yamada and K. Yano, Microporous Mesoporous Mater., 2006, 93, 190; (e) W. Guo, D.-C. Goh and X. S. Zhao, J. Mater. Chem., 2005, 15, 4112; $(f)$ M. D. McInall, J. Scott, L. Mercier and P. J. Kooyman, Chem. Commun., 2001, 2282; $(g)$ Y. Zhou and M. Antonietti, $A d v$. Mater., 2003, 15, 1452; (h) Y. Zhou and M. Antonietti, Chem. Mater., 2004, 16, 544; (i) S. A. Bagshaw and A. R. Hayman, Chem. Commun., 2000, 533; (j) R. I. Nooney, D. Thirunavukkarasu, A. Ostafin, Y. Chen and R. Josephs, Microporous Mesoporous Mater., 2004, 75, 183; (k) Z. Zhang, X. Yan, B. Tian, C. Yu, B. Tu, G. Zhu, S. Qiu and D. Zhao, Microporous Mesoporous Mater., 2006, 90, 23; (l) L. Huerta, F. Romero-Sarria, O. Marie, C. Guillem, A. Beltrán, J. Latorre, D. Beltrán and P. Amorós, Eur. J. Inorg. Chem., 2006, 3147; $(m)$ M. Kato, T. Shigeno, T. Kimura and K. Kuroda, Chem. Mater., 2005, 17, 6416.

8 (a) T. Asefa, M. Kruk, M. J. MacLachlan, N. Coombs, H. Grondey, M. Jaroniec and G. A. Ozin, J. Am. Chem. Soc., 2001, 123, 8520; (b) Q. Yang, M. P. Kapoor and S. Inagaki, J. Am. Chem. Soc., 2002, 124, 9694.

9 (a) S. L. Burkett, S. D. Sims and S. Mann, Chem. Commun., 1996, 1367; (b) D. J. Macquarrie, Chem. Commun., 1996, 1961.

10 L. Zhang, H. C. L. Abbenhuis, Q. H. Yang, Y.-M. Wang, P. C. M. M. Magusin, B. Mezari, R. A. V. Santen and C. Li, Angew. Chem., Int. Ed., 2007, 46, 5003.

11 M. Kruk and M. Jaroniec, Chem. Mater., 2001, 13, 3169.

12 (a) D. Zhao, Q. Huo, J. Feng, B. F. Chmelka and G. D. Stucky, J. Am. Chem. Soc., 1998, 120, 6024; (b) S. A. El-Safty, J. Colloid Interface Sci., 2003, 260, 184.

13 (a) J. Morell, M. Gungerich, G. Wolter, J. Jiao, M. Hunger, P. J. Klar and M. Fröba, J. Mater. Chem., 2006, 16, 2809; (b) M. P. Kapoor, N. Setoyama, Q. Yang, M. Ohashi and S. Inagaki, Langmuir, 2005, 21, 443; (c) M. C. Burleigh, S. Jayasundera, C. W. Thomas, M. S. Spector, M. A. Markowitz and B. P. Gaber, Colloid Polym. Sci., 2004, 282, 728.

14 (a) S. A. Bagshaw, E. Prouzet and T. J. Pinnavaia, Science, 1995, 269, 1242; (b) G. Herrier, J.-L. Blin and B.-L. Su, Langmuir, 2001, 17, 4422.

15 R. M. Laine, J. Mater. Chem., 2005, 15, 3725.

16 K. Landskron and G. A. Ozin, Science, 2004, 306, 1529.

17 (a) S. Inagaki, S. Guan, T. Ohsuna and O. Terasaki, Nature, 2002, 416, 304; (b) M. P. Kapoor, Q. Yang and S. Inagaki, J. Am. Chem. Soc., 2002, 124, 15176; (c) Y. Xia, W. Wang and R. Mokaya, J. Am. Chem. Soc., 2005, 127, 790; (d) A. Sayari and W. Wang, J. Am. Chem. Soc., 2005, 127, 12194.

18 (a) Y. Fang and H. Hu, J. Am. Chem. Soc., 2006, 128, 10637; (b) Y. Xia and R. Mokaya, J. Phys. Chem. B, 2006, 110, 9122; (c) S. C. Christiansen, D. Zhao, M. T. Janicke, C. C. Landry, G. D. Stucky and B. F. Chmelka, J. Am. Chem. Soc., 2001, 123, 4519; (d) D. T. On and S. Kaliaguine, Angew. Chem., Int. Ed., 2001, 40, 3248.

19 C. Zhang, F. Babonneau, C. Bonhomme, R. M. Laine, C. L. Soles, H. A. Hristov and A. F. Yee, J. Am. Chem. Soc., 1998, 120, 8380.

20 M. H. Lim, C. F. Blanford and A. Stein, J. Am. Chem. Soc., 1997, 119, 4090 .

21 L. Zhang, Q. H. Yang, W. H. Zhang, Y. Li, J. Yang, D. Jiang, G. Zhu and C. Li, J. Mater. Chem., 2005, 15, 2562.

22 (a) H. Wang, Y. Liu and T. J. Pinnavaia, J. Phys. Chem. B, 2006, 110, 4524; (b) Y. Liu, W. Zhang and T. J. Pinnavaia, Angew. Chem., Int. Ed., 2001, 40, 1255; (c) K. R. Kloetstra, H. V. Bekkum and J. C. Jansen, Chem. Commun., 1997, 2281; (d) Z. Zhang, Y. Han, F.-S. Xiao, S. Qiu, L. Zhu, R. Wang, Y. Yu, Z. Zhang, B. Zou, Y. Wang, H. Sun, D. Zhao and Y. Wei, J. Am. Chem. Soc., 2001, 123, 5014.

23 W. Guo, J.-Y. Park, M.-O. Oh, H.-W. Jeong, W.-J. Cho, I. Kim and C.-S. Ha, Chem. Mater., 2003, 15, 2295.

24 M. C. Burleigh, M. A. Markowitz, S. M. Jayasundera, S. Spector, C. W. Thomas and B. P. Gaber, J. Phys. Chem. B, 2003, 107, 12628.

25 M. H. Lim and A. Stein, Chem. Mater., 1999, 11, 3285.

26 (a) Y. Han, D. Li, L. Zhao, J. Song, X. Yang, N. Li, Y. Di, C. Li, S. Wu, X. Xu, X. Meng, K. Lin and F. S. Xiao, Angew. Chem., Int. Ed., 2003, 42, 3633; (b) D. Das, C.-M. Tsai and S. Cheng, Chem. Commun., 1999, 473; (c) J. Zheng, S. Zhai, Y. Zhang, D. Wu, Y. Sun, Y. Yang, L. Chen and F. Deng, Catal. Today, 2004, 93-95, 
529; (d) Y. Li, J. Shi, Z. Hua, H. Chen, M. Ruan and D. Yan, Nano Lett., 2003, 3, 609.

27 (a) H. Q. Yang, G. Y. Zhang, X. L. Hong and Y. Y. Zhu, Microporous Mesoporous Mater., 2004, 68, 119; (b) J. Liu, Q. H. Yang, M. P. Kapoor, N. Setoyama, S. Inagaki, J. Yang and L. Zhang, J. Phys. Chem. B, 2005, 109, 12250; (c) Q. H. Yang, Y. Li, L. Zhang, J. Yang, J. Liu and C. Li, J. Phys. Chem. B, 2004, 108, 7934; (d) W. Guo, X. Li and X. S. Zhao, Microporous Mesoporous Mater., 2006, 93, 285; (e) E.-B. Cho and K. Char, Chem. Mater., 2004, 16, 270.

\section{Find a SOLUTION ... with books from the RSC}

Choose from exciting textbooks, research level books or reference books in a wide range of subject areas, including:

- Biological science

- Food and nutrition

- Materials and nanoscience

- Analytical and environmental sciences

- Organic, inorganic and physical chemistry

\section{Look out for $\mathbf{3}$ new series coming soon ...}

- RSC Nanoscience \& Nanotechnology Series

- Issues in Toxicology

- RSC Biomolecular Sciences Series
NANOCHEMISTRY

AChemical Approsch to Nanomateriis

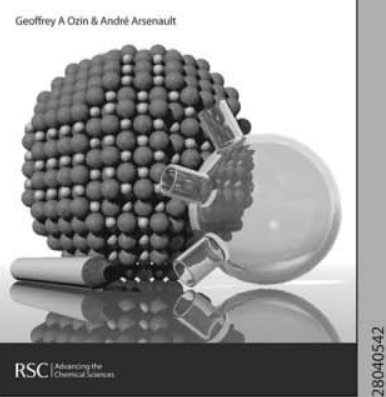

